\title{
Türkiye’ de Öğrenim Gören Yabancı Uyruklu Öğrencilerinin Atılganlık Düzeylerinin İncelenmesi
}

\author{
Sihmehmet YĭĞiT ${ }^{1 *} \mathbb{D}$ \\ İbrahim DALBUDAK ${ }^{2}$ \\ ${ }^{1}$ Namık Kemal Üniversitesi Beden Eğitimi ve Spor Yüksekokulu, TEKIRDA $\breve{G}$ \\ ${ }^{2}$ Isparta Uygulamalı Bilimler Üniversitesi, Atabey Meslek Yüksekokulu, ISPARTA \\ ${ }^{3}$ Uşak Üniversitesi Spor Bilimleri Fakültesi, UŞAK
}

Mihriay MUSA ${ }^{3}$

DOI: 10.31680/gaunjss.508139

Orijinal Makale / Original Article

Geliş Tarihi / Received: 04.01.2019 Kabul Tarihi / Accepted: 29.04.2019ＹＹayın Tarihi / Published: 28.06.2019

\section{Öz}

Üniversitede okuyan yabancı uyruklu öğrencilerin atılganlık düzeylerinin ortaya konulması ve farklı değişkenler açısından incelenmesi amaçlanmıştır. Araştırmanın örneklemini 2016-2017 eğitim-öğretim yılında Uşak Üniversitesinde farklı bölümlerde öğrenim gören 113 Erkek 35 Kadın toplam 148 yabancı uyruklu öğrenci oluşturmaktadır. Verilerin toplanmasında sosyo demografik özellikleri belirlemeye yönelik kişisel bilgi formu ile Voltan (1980) tarafından geçerlilik ve güvenirliliği yapılmış Rathus Atılganlık Ölçeği kullanıımıştı. Elde edilen verilerin analizi SPSS 22.00 İstatistik paket programıyla, diğer değişkenler ise tek yönlü varyans (ANOVA) analizi ile incelenmiştir. Anlamlı farkın olması durumunda varyans analiz sonuçları Tukey testi kullanılarak karşılaştırımış̧ı. Araştırmanın sonucunda; Uşak Üniversitesinde okuyan yabancı uyruklu öğrencilerin demografik özelliklerine göre atılganlık düzeyleri incelenmiş ve değerlendirilmiştir. Değerlendirmeler sonucunda; yaş, cinsiyet, uyruklarına göre, okudukları sınıf, düzenli spor yapıp yapmama durumuna göre, kaç yıldır spor yaptıklarına bakıldığında anlamlı farklılaşmaların olmadığı görülmüştür. Sonuç olarak; öğrencilerin hayata daha anlamlı bir şekilde tutunabilmelerinin sağlanması atılganlık düzeylerinin tespiti açısından önemli olduğu düşünülmektedir.

Anahtar Kelimeler: Spor, atılganlık, yabancı uyruklu öğrenci

\section{Investigation of Assertiveness Levels of Foreign Students Studying in Turkey}

\begin{abstract}
The aim of the study: It was aimed to reveal the level of assertiveness of foreign students studying at the university and to examine them in terms of different variables. The sample of the study consisted of 148 male students (113 male and 35 female) studying at Uşak University during the 2016-2017 school year. A personal information form was used to determine the socio-demographic characteristics in the data collection and Rathus Assertiveness Scale of which validity and reliability studies were conducted by Voltan (1980) were used. The data were analyzed with SPSS 22.00 statistical package program and the other variables were analyzed by oneway variance (ANOVA) analysis. In the case of significant difference, the variance analysis results were compared using the Tukey test. As a result of the research; the level of assertiveness of the foreign students studying at Uşak University according to their demographic characteristics has been examined and evaluated. As a result of the evaluations; they did not show significant differences according to age, gender, country, the grade they read, whether they regularly do sports or not, how many years of sports they have done. The concept of assertiveness is thought to be important in terms of determining the level of assertiveness to ensure that students can hold on to life more meaningfully.
\end{abstract}

Keywords: Sports, assertiveness, student.

\footnotetext{
* Sorumlu Yazar: Sihmehmet Yİ̈̆iT
}

E-mail: smehmetyigit27@hotmail.com 
Yiğit, S., Dalbudak, İ ve Musa, M. (2019). Türkiye' de Öğrenim Gören Yabancı Uyruklu Öğrencilerinin Atılganlık Düzeylerinin İncelenmesi. Gaziantep Üniversitesi Spor Bilimleri Dergisi, 4(2), 190-198.

\section{Giriş}

Atılganlık kavramı ilk olarak Wolpe ve Lazarus (1966), tarafından tanımlamıştır. Atılganlık kavramının bugün kullanılan tanımı ise Alberti ve Emmons (2002), tarafından yapılmış ve atılgan kişiyi kendi haklarını iyi bilen ve savunabilen kişi olarak tanımlamışlardır (Ayhan, 2012). "Assertivenes" sözcük anlamıyla kendine güvenme demektir. Güvenli davranış, başkalarının haklarını çiğnemeden kendi haklarını savunabilmek, duygu, düşünce ve inançlarını uygun yollarla ifade edebilmek, bilinçli ve yapıcı iletişim kurmak anlamına gelmektedir (Kaplanoğlu, 2006). Atılganlık; 'girişken olmak', 'kendini açık olarak ortaya koymak', 'etkin davranmak', anlamlarına gelmektedir. Kişilerarası bir ilişki biçimi olan atılganlık, başkalarını küçük görmeden, haklarını yadsımadan kişinin kendi haklarını korumasını içermektedir. Atılganlık eğitimi ise öğrencilerin çeşitli becerilerini geliştirmeyi amaçlamaktadır. Atılganlık genel olarak; uygun bir çerçeve içinde açık, dolaysız ve dürüst bir iletişim kurma biçimidir (Dinçer, 2005). Başkalarını küçük görmeden, onların haklarını yadsımadan, bireyin kendi haklarını koruyabilme, duygu ve düşüncelerini açıkça anlatabilme yolu olarak geliştirilen bir çeşit kişiler arası ilişkiler biçimi olarak tanımlanabilir (Kamaraj, 2004; Toruncu, 1994). Wolpe ve Lazarus (1966) atılganlığı, kişisel hakların duygu ve düşüncelerin sosyal açıdan kabul edilebilir tüm biçimi olarak tanımlanmıştır.

Atılganlık, "dogmatik ya da saldırgan iddialarda bulunma" olarak tanımlanmaktadır (Mcleod,1987). Atılgan bireyler diğer bireylerin hakları olduğunun bilincinde olan, bunun yanında kendi haklarını da bilip, diğer kişilerin haklarını çiğnemeden kendi haklarını kullanabilen bireylerdir (Arı, 1989). Alberti ve Emmons şunu söylemişlerdir; atılganlığın ölçülmesindeki en büyük sorun onun tanımlanması güç bir kavram olmasıdır. İnsana ait herhangi bir özelliğe parmak basarak "işte atılganlık budur" diyemeyiz. Bu karmaşık olgu hem ilgili insanlara, hem de onların içinde bulundukları durumlara bağlı olarak değişkenlik gösterir (Alberti ve Emmons 2002). Atılgan bireylerin atılgan olmayanlara kıyasla yüksek benlik ve algı değerine sahip olduğunu düşünür (Bal, 2006). Belli bir duruma özgü atılgan olamama davranışı sergileyen kişiler sadece kendileri için özel durumlarda bu tür bir iletişimi dışa yansıtırlar. Örneğin, otorite karşısında gerginlik hisseden kişiler, arkadaş ilişkilerinde atılgan davranabildiği halde, üstü konumundaki kişilerle olan ilişkilerinde kendilerini rahatlıkla ifade edemezler (Alberti, 2002). Bireyler arası ilişkiler incelendiğinde, bazı bireylerin ilişkilerinde daha güven verici oldukları, duygu ve 
Yiğit, S., Dalbudak, İ ve Musa, M. (2019). Türkiye' de Öğrenim Gören Yabancı Uyruklu Öğrencilerinin Atılganlık Düzeylerinin İncelenmesi. Gaziantep Üniversitesi Spor Bilimleri Dergisi, 4(2), 190-198.

düşüncelerini daha rahat biçimde ortaya koydukları görülmektedir. Bu bireylere söz konusu özelliklerinden dolayı "atılgan bireyler" denilmekte ve diğer kişiler tarafından saygı duyulmaktadır (Aydın, 1991). Bu araştırmanın amacı; Uşak üniversitesinde eğitim gören yabancı uyruklu öğrencilerin atılganlık düzeylerinin çeşitli değişkenlere göre farklılık gösterip göstermediğini inceleyip değerlendirmektir.

\section{Yöntem}

\section{Araştırma Grubu}

Araştırma grubunu Uşak Üniversitesinde öğrenim gören yabancı uyruklu örgencilerin atılganlık düzeylerinin ortaya konulması ve sosyo demografik özellikler açısından araştıııması amacıyla 113 erkek, 35 kadın toplam 148 farklı ülkelerden gelen yabancı uyruklu öğrenci oluşturmaktadır.

\section{Verilerin Toplanması}

Araştırmanın amacına ilişkin mevcut bilgiler, literatürün taranmasıyla sistematik bir şekilde verilmiştir. Çalışmanın amacına ulaşabilmek için öğrencilere araştırmacı tarafından hazırlanan sosyo demografik özellikleri belirlemeye yönelik kişisel bilgi formu ile Rathus tarafından (1973) yılında geliştirilen, Voltan Acar (1980) tarafından Türkçeye uyarlanması yapılan geçerlilik ve güvenirliliği yapılmış olan Rathus Atılganlık Ölçeği (RAÖ) ölçeği kullanılımıştır. (RAÖ) olumlu ve olumsuz toplam 30 maddeden oluşan bu ölçek; "Bana çok iyi uyuyor", "Bana oldukça uyuyor", "Bana biraz uyuyor", "Bana pek uymuyor", "Bana oldukça uymuyor" ve "Bana hiç uymuyor" biçiminde işaretlenebilen 6’lı Likert türü ifadelerden oluşmaktadır.

\section{Verilerin Analizi}

Veri analizine geçilmeden önce analiz varsayımları incelenmiştir. Kayıp ve yanlış kodlamalardan veriler arındırılmış ve normallik varsayımı basıklık ve çarpıklık değeri ile test edilmiştir. Ardından, cinsiyet ve katılımcıların spor yapıp yapmadıkları bağımsız örneklemler için $t$ testi; diğer değişkenler ise tek yönlü varyans (ANOVA) analizi ile incelenmiştir. Anlamlı farkın olması durumunda varyans analiz sonuçları Tukey testi kullanılarak karşılaştırılmıştır. Analizler SPSS 22.00 ve. 05 anlamlılık düzeyi ile test edilmiştir. 


\section{Bulgular}

Tablo 1' de katılımcıların atılganlık düzeylerine ilişkin tanımlayıcı istatistikler verilmiştir. Değişkene ilişkin basıklık ve çarpıklık değerlerinin .-.928 ve. 045 olduğu ve bu değerlerin -1 ile +1 Aralığında olduğu görülmektedir. Bu nedenle değişkenin normal dağılıma sahip olduğu söylenebilir.

Tablo 1. Atılganlık düzeyine ilişkin tanımlayıcı istatistikler

\begin{tabular}{cccccc}
\hline Değişken & N & Ortalama & Ss. & Basıklık & Çarpıklık \\
\hline Atılganlık düzeyi & 148 & 102,6284 & 11,23120 &,- 928 & .045 \\
\hline
\end{tabular}

Katılımcıların cinsiyete göre atılganlık düzeylerine ilişkin yapılan bağımsız örneklemler için t-testi bulguları Tablo 1'de verilmiştir.

Tablo 2. Katılımcıların atılganlık düzeyi düzeyleri ve cinsiyet değişkenine Illişkin T Testi Tablosu

\begin{tabular}{ccccccc}
\hline Cinsiyet & $\mathrm{N}$ & Ortalama & Ss & $\mathrm{t}$ & $\mathrm{sd}$ & $\mathrm{p}$ \\
\hline Erkek & 113 & 102,0531 & 11,83958 & $-1,121$ & 146 &, 264 \\
Kadın & 35 & 104,4857 & 8,88611 & & & \\
\hline
\end{tabular}

Katıımcıların atılganlık düzeyinin cinsiyete göre değişip değişmediğine ilişkin bulgular, cinsiyete göre katılımcıların atılganlık düzeyinde almalı bir farklılaşmanın olmadığını göstermiştir (t (146) = -1.121, p > .05)

Tablo 3. Yaşa göre katıımcıların atılganlık düzeyine ilişkin Anova Testi Tablosu

\begin{tabular}{cccccc}
\hline & Kareler Ortalaması & sd & Kareler Ortalaması & $\mathrm{F}$ & $\mathrm{p}$ \\
\hline Gruplar arası & 5,141 & 2 & 2,571 &, 020 &, 980 \\
Grup içi & 18537,420 & 145 & 127,844 & & \\
Toplam & 18542,561 & 147 & & & \\
\hline
\end{tabular}

Katılımcıların yaş ve atılganlık düzeyine ilişkin tek yönlü ANOVA sonuçları incelendiğinde, yaş açısından katııımıların atılganlık düzeylerinde almalı şekilde bir farklılaşmanın olmadığı görülmektedir $(F(2,145)=.020 p>.05)$.

Tablo 4. Katılımcıların ülkelerine göre atılganlık düzeyine ilişkin bulgular Anova Testi Tablosu

\begin{tabular}{cccccc}
\hline & Kareler Ortalaması & sd & Kareler Ortalaması & $\mathrm{F}$ & $\mathrm{p}$ \\
\hline Gruplar arası & 388,480 & 4 & 97,120 &, 765 &, 550 \\
Grup içi & 18154,081 & 143 & 126,952 & & \\
Toplam & 18542,561 & 147 & & & \\
\hline
\end{tabular}


Yiğit, S., Dalbudak, İ ve Musa, M. (2019). Türkiye' de Öğrenim Gören Yabancı Uyruklu Öğrencilerinin Atılganlık Düzeylerinin İncelenmesi. Gaziantep Üniversitesi Spor Bilimleri Dergisi, 4(2), 190-198.

Katılımcıların geldikleri ülkeye göre benlik saygılarına ilişkin bulgular, atılganlık düzeyinin katılımcıların ülkelerine göre anlamlı şekilde farklılaşmadığını göstermiştir $(F(4,143)=.765, p<.05)$.

Tablo 5. Okudukları sınıfa göre katılımcıların atılganlık düzeyine ilişkin Anova Testi Tablosu

\begin{tabular}{cccccc}
\hline & Kareler Ortalaması & sd & Kareler Ortalaması & F & p \\
\hline Gruplar arası & 666,976 & 2 & 333,488 & 2,705 &, 070 \\
Grup içi & 17875,585 & 145 & 123,280 & & \\
Toplam & 18542,561 & 147 & & &
\end{tabular}

Katılımcıların sınıf düzeyine ilişkin tek yönlü ANOVA sonuçları, sınıf düzeyi açısından katılımcıların benlik saygılarında almalı bir farklılaşmanın olmadığını göstermiştir $(F(2,145)=2.705, p>.05)$.

Tablo 6. Katılımcıların atılganlık düzeyi düzeyleri ve spor yapma durumuna ilişkin T Testi Tablosu

\begin{tabular}{ccccccc}
\hline $\begin{array}{c}\text { Spor } \\
\text { Durumuna }\end{array}$ & $\mathrm{N}$ & Ortalama & Ss & $\mathrm{t}$ & $\mathrm{sd}$ & $\mathrm{p}$ \\
\hline Evet & 86 & 103,1047 & 12,18488 &, 606 & 146 &, 545 \\
Hayır & 62 & 101,9677 & 9,81462 & & & \\
\hline
\end{tabular}

Katılımcıların spor yapıp yapmadığına göre atılganlık düzeylerine ilişkin yapılan t testi sonuçları incelendiğinde, spor yama ve yapmamaya göre katılımcıların atılganlık düzeyinde anlamlı bir farklılaşmanın olmadığı görülmüştür (t $(146)=.606, p$ $>$.05).

Tablo 7. Spor yaptığı süreye göre atılganlık düzeyine ilişkin Anova Testi Tablosu

\begin{tabular}{cccccc}
\hline & Kareler Ortalaması & sd & Kareler Ortalaması & F & $p$ \\
\hline Gruplar arası & 394,460 & 3 & 131,487 & 1,043 &, 375 \\
Grup içi & 18148,101 & 144 & 126,028 & & \\
Toplam & 18542,561 & 147 & & &
\end{tabular}

Katılımcıların atılganlık düzeyinin spor yapma süresine göre anlamlı şekilde farklılaşıp farklılaşmadığına ilişkin varyans (ANOVA) analiz sonuçları, yapılan spor süresine göre atılganlık düzeyinde anlamlı bir farklılaşmanın olmadığını göstermiştir $(F(3,144)=1.043, p>.05)$. 
Yiğit, S., Dalbudak, İ ve Musa, M. (2019). Türkiye' de Öğrenim Gören Yabancı Uyruklu Öğrencilerinin Atılganlık Düzeylerinin İncelenmesi. Gaziantep Üniversitesi Spor Bilimleri Dergisi, 4(2), 190-198.

\section{Tartışma ve Sonuç}

$\mathrm{Bu}$ çalışma üniversite öğrencilerinin atılganlık düzeylerinin özlük niteliklerine göre ortaya konulması ve sosyo demografik özelliklere göre atılganlık düzeylerinin farklılık gösterip göstermediğinin incelenmesi amaçlanmıştır. Araştırmanın ikincil amacı ise demografik özellikler: yaş, cinsiyet, katılımcıların ülkelerine göre, okudukları sınıf, düzenli spor yapıp yapmama durumuna göre, kaç yıldır spor yaptıkları, itibariyle atılganlık düzeyleri arasında anlamlı bir farklıık veya ilişki olup olmadığını belirlemektir.

Voltan (1980), bir araştırmasında, kendini anlatma, isteklerini elde etme ve duygularını açığa vurma konularında kırsal kesimlerde yetişen sosyal ve ekonomik seviyesi düşük aile içerisinde yetişen 70 üniversite öğrencilerinin, üst sosyoekonomik düzeye sahip şehirlerde oturan öğrencilere göre daha yetersiz ve çekingen kişilik özelliğine sahip olduklarını bulmuştur. Ayrıca bu araştırmada, deneklerin grup içindeki atılgan davranış düzeylerinin yalnız bulundukları durumlara göre daha yüksek olduğunu göstermektedir.

Bazı araştırmalarda atılgan ve saldırgan davranışın kültürden kültüre farklı algılanabildiği, kültürün farklı cinsiyetlere yüklediği rollerin, cinsiyetin ortaya koyduğu davranışın algılanışını etkilediği belirtilmiştir. Örneğin; Furnham (1979), yaptığı çalışmada üç alt kültüre ait atılganlık farklılıklarını ve her kültür içinde atılganlık kavramının kapsadığı çok yönlülüğü araştırmıştır. Bu araştırmaya göre, Avrupalıların atılganlık düzeyi son derce yüksek, Hintlilerin son derece düşük, Afrikalıların ise ikisinin arasında bir atılganlık değerine sahip olduğu görülmüştür. Kültürümüzde aynı tepkiyi verdiğinde bir erkek atılgan olarak değerlendirilirken ve onaylanırken, bir kadın ise saldırgan olarak değerlendirilerek onaylanmamaktadır.

Türk gençleri ile İsveçli gençlerin atılganlık düzeylerini karşılaştıran bir çalışmada (Eşkin, 2003), İsveçli gençlerin daha atılgan oldukları ve özgüvenlerinin daha yüksek olduğu saptanmıştır. Bu çalışmada erkek ve kadınların atılganlık düzeyi incelendiğinde sanılanın aksine her iki kültürde de kadınların daha atılgan, cesur ve yüksek özgüven sahibi oldukları gözlenmiştir. Üniversite öğrencileri üzerinde yapmış olduğu çalışmasında ise, atılganlık düzeyi ve beden algısından sağlanan doyum arasındaki ilişki araştırımış aynı zamanda atılganlık düzeyi ve beden algısı konuları çeşitli sosyo demografik değişkenler açısından incelenmiştir. Araştırma sonucuna göre; atılganlık düzeyi ile beden algısından hoşnut olma düzeyi arasında anlamlı ilişki olduğu; Edebiyat Fakültesinde okuyan deneklerin atılganlık düzeyinin diğer deneklere 
Yiğit, S., Dalbudak, İ ve Musa, M. (2019). Türkiye' de Öğrenim Gören Yabancı Uyruklu Öğrencilerinin Atılganlık Düzeylerinin İncelenmesi. Gaziantep Üniversitesi Spor Bilimleri Dergisi, 4(2), 190-198.

göre yüksek olduğu saptanmıştır (Uğurlu, 1994). Buradan da anlaşılıyor ki atılganlık sadece kültür ile bağlantılı olmayıp, kültürün etkisi altında ebeveyn olarak anne ve babaların çocuklarını yetiştirirken onlara yükledikleri rol ve sorumluluklar çocuğun öz güvenini olumlu veya olumsuz pekiştirmektedir.

Kul ve Demirel (2017), çalışmalarında erkeklerde ve kadınlarda atılganlık farklarının olup olmadığını incelemişler ve iki cinsiyet arasında anlamlı bir farklılı̆ın olmadığını belirtmişlerdir. Eraslan (2015), üniversite spor bölümü öğrencilerinin atılganlık ve karar verme stillerinin çeşitli değişkenlere göre incelendiği çalışmada lisanslı olarak spor yapan ve yapmayan üniversite öğrencilerinin atılganlık düzeyleri arasında anlamlı farklılıklar tespit etmediğini belirtmiştir. Gündoğdu ve ark. (2016), çalışmasında gençlerin spor yapma ve yapmama durumlarına göre atılganlık düzeyleri benzerlik gösterdiğini belirtmiştir.

Araştırma sonucunda; yaş, cinsiyet, ülkelere göre, okudukları sınıf, düzenli spor yapıp yapmama durumuna göre, kaç yıldır spor yaptıklarına bakıldığında anlamlı farklılaşmaların olmadığı görülmüştür. Taranan literatürden elde edilen sonuçlara bakıldığında bu çalışmayla aynı sonuçlara ulaşılmış olan bazı kaynaklara yer verilmiştir. Atılgan olmaları beklenen üniversite öğrencilerinin çekingen olması yaşam kalitesini, öğrenimlerini olumsuz yönden etkilemektedir. Yabancı uyruklu üniversite öğrencileri farklı kültürlerden gelip Türkiye'de eğitim gördükleri için sosyal ilişkileri yetersiz ve sınırlı düzeydedir. Bu öğrencilere öğrenimleri süresince atılganlık eğitimleri verilerek atılganlık düzeylerinin artııımasına destek verilmelidir. Çalışmamıza katılan yabancı uyruklu öğrencilerin sosyo demografik özellikler açısından bakıldığında anlamlı farklılaşmaların olmadığı görülmüştür. Sonuç olarak; öğrencilerin atılganlık düzeylerinin gelişmesi için onlara uygun koşul ve ortamların sağlanması oldukça önemlidir. Atılganlık kavramı öğrencilerin hayata daha anlamlı bir şekilde tutunabilmelerini sağlanması atılganlık düzeylerinin tespiti açısından önemli olduğu düşünülmektedir.

\section{Kaynaklar}

Alberti, R. \& Emmons, M. (2002). Atılganlık "Kendinize Yatırım Yapın" .Hyb Yayıncılık, , s.6-32-55-57-63. (Çev: Serap Katlan) Ankara.

Arı, R. (1989). Üniversite öğrencilerinin baskın ben durumları ile bazı özlük niteliklerinin ben durumlarına, atılganlık ve uyum düzeylerine etkisi. Yayınlanmamış Doktora Tezi. H.Ü. Sosyal Bilimler Enstitüsü. Ankara. 
Yiğit, S., Dalbudak, İ ve Musa, M. (2019). Türkiye' de Öğrenim Gören Yabancı Uyruklu Öğrencilerinin Atılganlık Düzeylerinin İncelenmesi. Gaziantep Üniversitesi Spor Bilimleri Dergisi, 4(2), 190-198.

Aydın, B. (1991). Cinsiyet ve Cinsiyet Rolleri Açısından Atılganlık Seviyesinin İncelenmesi. Marmara Üniversitesi, Atatürk Eğitim Fakültesi Dergisi. 3:25-36.

Ayhan G. (2012). Hemşirelerde psikolojik şiddet (mobbing) ile atılganlık düzeyi ilişkisi. Ege Üniversitesi Sağlık Bilimleri Enstitüsü, İzmir, Yüksek Lisans Tezi. İzmir.

Bal, E. (2006). İlköğretim Öğrencilerinin Benlik Algıları İle Atılganlık Düzeyleri Arasındaki İlişkilerin İncelenmesi. Yayımlanmamış Yüksek Lisans Tezi. Marmara Üniversitesi, Eğitim Bilimleri Enstitüsü, İstanbul.

Dinçer, M. (2005). Kişilerarası İletişimde Sorun Çözücü Bir iletişim Becerisi Olarak Atılganlık. Edi: Gürüz D, Temel A. İletişime Yeni Yaklaşımlar. Nobel Basımevi, 1. Baskı, s.25-56. İzmir.

Eraslan E. (2015).Üniversite spor bölümü öğrencilerinin atılganlık ve karar verme stillerinin çeşitli değişkenlere göre incelenmesi. Bartın Üniversitesi Eğitim Fakültesi Dergisi;4(1):214-223.

Eşkin, M. (2003). Self-reportedassertiveness in swedishand turkis hadolescents: A cross-culturalcomparison. Scandinavian Journal Of Psychology, 44(1): 7-12.

Furnham, A. (1979). Assertiveness in three cultures: Multidimensionality and cultural differences. Journal of Clinical Psychology, 35: 522- 527.

Gündoğdu, C,. Tüfekçi, Ş,. \& Çelebi, E. (2016). Gençlik merkezlerine üye olan gençlerin atılganlık düzeylerinin incelenmesi. İnönü Üniversitesi Beden Eğitimi ve Spor Bilimleri Dergisi;3(1):1-9.

Kamaraj, I. (2004). Sosyal beceri değerlendirme ölçeğinin türkçeye uyarlanması ve beş yaş çocuklarının atılganlık sosyal Becerisini kazanmalarında eğitimci drama programının etkisi. Yayınlanmamış Doktora Tezi. Marmara Üniversitesi, Eğitim Bilimleri Enstitüsü, İstanbul.

Kaplanoğlu A. E. (2006). Yönetici Hemşirelerin Atılganlık Düzeyleri ile İş Doyumları Arasındaki İlişki. Marmara Üniversitesi Sağlık Bilimleri Enstitüsü, Yüksek Lisans Tezi. İstanbul.

Kul M, \& Demirel M. (2015). Lise öğrencilerinin spor değişkenine göre sosyal beceri ve atılganlık düzeylerinin karşılaştırıması. International Journal of Cultural and Social Studies (IntJCSS);1:41-54.

Mcleod, (1987). K. Wilson \& C. Gallois (1993). Assertion and Its Social Context. Pergamon Press. 
Yiğit, S., Dalbudak, İ ve Musa, M. (2019). Türkiye' de Öğrenim Gören Yabanc1 Uyruklu Öğrencilerinin Atılganlık Düzeylerinin İncelenmesi. Gaziantep Üniversitesi Spor Bilimleri Dergisi, 4(2), 190-198.

Toruncu, B. (1994). Eğitim Sürecinde Grupla Danışmanlık Uygulamalarının Gençlerin Girişimcilik Gelişimine Etkisi. (Yenişehir Sağlık Meslek Lisesinde Deneysel Bir Uygulama). Yayımlanmamış Yüksek Lisans Tezi. Dokuz Eylül Üniversitesi, Sosyal Bilimler Enstitüsü, İzmir.

Uğurlu, U. (1994). Yetiştirme Yurdunda Yaşayan Ergenler ile Ailesi ile Birlikte Yaşayan Ergenlerin Özsaygı ve Atılganlık Düzeyleri Açısından Karşılaştırılması. Yayımlanmamış Yüksek Lisans Tezi. Atatürk Üniversitesi. Erzurum.

Voltan, N. (1980). Rathus Atılganlık Envanteri geçerlik ve güvenirlik çalışması. Psikoloji Dergisi, 10: 23-25.

Voltan, N. (1980). Grupla Atılganlık Eğitiminin Bireyin Atılganlık Düzeyine Etkisi. Hacettepe Üniversitesi Psikolojik Danışma ve Rehberlik Bölümü. Doktora Tezi. Ankara.

Wolpe, J. \& Lazarus, A. (1966). Behavior Therapy Techniques, Oxford, Pergamman Pres. 